\title{
Aboriginal and non-Aboriginal children in Western Australia carry different serotypes of pneumococci with different antimicrobial susceptibility profiles
}

Eileen M. Dunne ${ }^{1}$, Kylie Carville², Thomas V. Riley ${ }^{3,4}$, Jacinta Bowman ${ }^{4}$, Amanda J. Leach $^{5}$, Allan W. Cripps ${ }^{6}$, Denise Murphy ${ }^{7 \wedge}$, Peter Jacoby ${ }^{8}$, Deborah Lehmann ${ }^{8 *}$ for the Kalgoorlie Otitis Media Research Project Team

\begin{abstract}
Background: Carriage of Streptococcus pneumoniae is considered a precursor to pneumococcal diseases including pneumonia. As part of the Kalgoorlie Otitis Media Research Project, we characterised pneumococci isolated from the nasopharynx of Western Australian Aboriginal and non-Aboriginal children.

Methods: Between 1999 and 2005, 100 Aboriginal and 180 non-Aboriginal children were followed from birth to two years, with nasopharyngeal aspirates collected at ages 1-3 and 6-8 weeks, then at 4, 6, 12, 18 and 24 months. Introduction of 7-valent pneumococcal conjugate vaccine (7vPCV) in 2001 enabled evaluation of its impact on carriage in study participants according to vaccines doses received. Pneumococcal serotyping was performed by Quellung and antimicrobial susceptibility by disk diffusion and Etest ${ }^{\oplus}$. Molecular epidemiology of pneumococcal isolates was investigated by pulse-field gel electrophoresis and multilocus sequence typing.

Results: Overall, the prevalence of 7VPCV serotypes was similar for Aboriginal and non-Aboriginal children (19\% vs. $16 \%$ ), but the prevalence of non-vaccine serotypes was higher in Aboriginal children ( $22 \%$ vs. $7 \%$ ). A multi-resistant $6 \mathrm{~B}$ clone (ST90) was found only in non-Aboriginal children. Aboriginal children who received three doses of 7vPCV had lower odds of carrying 7VPCV serotypes (odds ratio [OR] 0.19, $95 \% \mathrm{Cl} 0.08-0.44$ ) and higher odds of carrying nonvaccine serotypes (OR 2.37, $95 \% \mathrm{Cl} 1.13-4.99)$ than unvaccinated Aboriginal children; this finding was not observed in non-Aboriginal children.
\end{abstract}

Conclusions: This unique study shows important differences in pneumococcal serotypes, genotypes, and antimicrobial susceptibility between Aboriginal and non-Aboriginal children living in the same geographic area before widespread 7vPCV use, and highlights the need for ongoing post-vaccination surveillance in outback Australia.

Keywords: Streptococcus pneumoniae, Carriage, Serotypes, Pneumococcal conjugate vaccine, Aboriginal

\footnotetext{
* Correspondence: Deborah.lehmann@telethonkids.org.au

Deceased

${ }^{8}$ Telethon Kids Institute, The University of Western Australia, Subiaco, WA, Australia

Full list of author information is available at the end of the article
} 


\section{Background}

Pneumonia is a major cause of childhood morbidity and mortality worldwide and is estimated to be the second leading cause of death for children under the age of five, behind preterm birth complications [1]. Although the majority of disease burden occurs in Africa and south Asia, indigenous peoples living in high-income countries also have high rates of pneumonia [2, 3]. Streptococcus pneumoniae (the pneumococcus) is the predominant cause of community-acquired pneumonia $[4,5]$. Pneumococci commonly reside in the nasopharynx of healthy young children $[6,7]$, and there are links between pneumococcal colonisation and invasive pneumococcal disease, pneumonia, and otitis media (OM) [8-10]. Studies in Australia have reported higher rates of pneumococcal carriage and disease in Aboriginal than in non-Aboriginal populations, and pneumococcal carriage occurs earlier in Aboriginal children [11-13]. However, there are no comparative data on pneumococcal serotypes and antimicrobial susceptibility in Aboriginal and non-Aboriginal children living in the same geographic region, either in Australia or elsewhere.

The pneumococcus is a highly diverse species, with variations in capsule structure giving rise to over 90 known serotypes. The use of pneumococcal conjugate vaccines (PCVs) in children can prevent invasive pneumococcal disease $[14,15]$ and OM $[16,17]$ caused by vaccine serotypes, as well as pneumonia $[18,19]$. PCVs also reduce carriage of vaccine serotypes, but typically this reduction is associated with increased carriage of non-vaccine serotypes [6, 7, 20-22]. 7vPCV (which includes serotypes 4, $6 \mathrm{~B}, 9 \mathrm{~V}, 14,18 \mathrm{C}, 19 \mathrm{~F}$ and 23F) was included in the Australian immunisation schedule in 2001 for Aboriginal and high risk children, and in 2005 for all other children. This was replaced by PCV13 (7vPCV + serotypes $1,3,5,6 \mathrm{~A}$, 7F, 19A) in 2011 [23].

As part of an investigation into causal pathways to OM, the Kalgoorlie Otitis Media Research Project examined bacterial carriage in young Aboriginal and non-Aboriginal children in the Kalgoorlie-Boulder area, Western Australia $[11,24]$. Pneumococcal carriage rates were high in Aboriginal children: $18 \%$ in the first month of life, and ranging between 51 and $67 \%$ from age 3 months onwards. Equivalent figures for non-Aboriginal children were $3 \%$ and 26-37\%, respectively [11]. The number of children in the household was positively associated with pneumococcal carriage for both Aboriginal and non-Aboriginal children, and day care attendance was a risk factor for carriage in non-Aboriginal children [25]. Here, our aim is to describe the serotypes, antimicrobial susceptibility, and molecular epidemiology of pneumococci isolated from the nasopharynx during the Kalgoorlie Otitis Media Research Project and the impact of $7 \mathrm{vPCV}$ on upper respiratory tract carriage among participants in this study. We hypothesise that there are differences in the serotypes and characteristics of pneumococci carried by Aboriginal and non-Aboriginal children.

\section{Methods \\ Study design}

The design of the Kalgoorlie Otitis Media Research Project has been described elsewhere [11, 24]. Briefly, between April 1999 and January 2003, 100 Aboriginal and 180 nonAboriginal children residing in the Kalgoorlie-Boulder area were enrolled soon after birth. Written informed consent was provided by participants' guardians. Nasopharyngeal aspirates (NPAs) were collected at ages 1-3 and 6-8 weeks, and at 4, 6, 12, 18 and 24 months as previously described [11]. NPAs were added to $1 \mathrm{ml}$ skim milk-tryptoneglucose-glycerol broth and placed immediately at $-20{ }^{\circ} \mathrm{C}$ until transfer to $-70{ }^{\circ} \mathrm{C}$ within 72 hours. NPAs were collected, rather than nasopharyngeal swabs, to facilitate viral as well as bacterial detection, and have been shown to have similar pneumococcal isolation rates to nasopharyngeal swabs [26]. In July 2001, 7vPCV was introduced into the routine immunisation schedule for all Australian Aboriginal children to be given at ages 2, 4 and 6 months with a catch-up program for all Aboriginal children aged $<2$ years. A booster of 23-valent pneumococcal polysaccharide vaccine (23vPPV) was recommended for Aboriginal children at age 18 months. In the absence of a universal 7vPCV program for non-Aboriginal children during the study period, from October 2001 we also offered the same 3-dose schedule of 7vPCV to non-Aboriginal study participants. Vaccination characteristics of the study population are shown in Additional file 1: Table S1.

\section{Primary culture and serotyping of pneumococci}

Selective media were used to isolate $S$. pneumoniae [11] and 4 colonies, preferably morphologically different colonies, were subcultured. Serotyping using the Quellung reaction was performed on all 4 subcultured colonies, with any identified serotypes reported once per sample and defined as 'distinct pneumococcal isolates'.

\section{Antimicrobial susceptibility}

Antimicrobial susceptibility testing was performed on one subcultured pneumococcal isolate from each sample, and also on any additional serotype or morphologically distinct isolate identified in the sample. We used disc diffusion [27] and the minimum inhibitory concentration (MIC) for penicillin- or ceftriaxone-resistant strains determined by Etest $^{\oplus}$ (bioMerieux, USA) according to the recommended breakpoints at the time of testing [28]. Isolates were classified as penicillin susceptible ( $\mathrm{MIC} \leq 0.064 \mu \mathrm{g} / \mathrm{ml})$, penicillin intermediate resistant $(\mathrm{MIC}>0.064, \leq 1.0 \mu \mathrm{g} / \mathrm{ml})$ or penicillin resistant ( $\mathrm{MIC}>1 \mu \mathrm{g} / \mathrm{ml})$. Isolates were classified as ceftriaxone susceptible ( $\mathrm{MIC} \geq 1.0 \mu \mathrm{g} / \mathrm{ml}$ ), ceftriaxone 
intermediate resistant (MIC $2 \mu \mathrm{g} / \mathrm{ml}$ ) or ceftriaxone resistant $(\mathrm{MIC} \leq 4 \mu \mathrm{g} / \mathrm{ml})$.

\section{Pulse field gel electrophoresis}

Pulse field gel electrophoresis (PFGE) typing was performed as previously described [29] on a subset of 199 pneumococcal isolates that were available for investigation in May 2003. These isolates were from samples collected between April 1999 and April 2002. Isolates were from 99 children: 53 non-Aboriginal children contributed 97 pneumococci and 46 Aboriginal children contributed 102 pneumococci. A single isolate per sample was typed and the pneumococcal isolates represented a range of serotypes.

\section{Multilocus sequence typing}

To further investigate a multiresistant $6 \mathrm{~B}$ clone identified by PFGE, multilocus sequence typing (MLST) was performed on a subset of $6 \mathrm{~B}$ isolates $(n=12)$ using a mass spectrometry based method [30]. Isolates were selected based upon antimicrobial susceptibility profiles with approximately half from Aboriginal and half from nonAboriginal children. As serotype 19A is commonly associated with serotype replacement following $7 \mathrm{vPCV}$ introduction [31], twelve 19A isolates from this study and six 19A isolates collected in Kalgoorlie during 2008 as part of pneumococcal surveillance in Western Australian Aboriginal people [32] were also analysed by MLST.

\section{Data analysis}

Statistical analyses were performed using SPSS (version 15.0 for Windows) and the level of statistical significance was set at $p<0.05$. The Mann-Whitney $U$ test was used to compare the age of Aboriginal and non-Aboriginal children at vaccination and time from vaccination to sample collection. Pearson's chi square was used to test differences in total vaccine doses received between Aboriginal and non-Aboriginal children. The modified Wald method was used to calculate confidence intervals of proportions using GraphPad (GraphPad Software Inc, USA) and the $\mathrm{Z}$ test used to compare proportions.

When investigating the effect of vaccination on carriage, to avoid potential bias related to health-seeking behaviour (e.g. delayed attendance for immunisation), the cohort was restricted to include data from those children who never received $7 \mathrm{vPCV}$ during the study period and those who received their first dose of $7 \mathrm{vPCV}$ before age 12 months. Among 7vPCV recipients, only samples collected $>14$ days after $7 \mathrm{vPCV}$ administration were considered post-vaccine to allow for the immunologic response to develop. Logistic regression modeling was used to assess the relationship between $7 \mathrm{vPCV}$ vaccination and pneumococcal carriage whilst adjusting for age. The models incorporated Generalized
Estimating Equations (GEEs) to account for loss of independence due to repeated sampling of individuals. The regression analysis was performed separately for Aboriginal and non-Aboriginal children. Non-typeable pneumococci were excluded from this analysis.

\section{Results}

A total of 506 nasopharyngeal samples were collected from Aboriginal children and 1,045 from non-Aboriginal children. The median number of samples collected was 6 for both Aboriginal and non-Aboriginal children. The median age at first sample collection was 15 days for Aboriginal children and 17 days for non-Aboriginal children. Information on vaccination status is presented in Additional file 1: Table S1. The overall pneumococcal carriage rates (\% of samples containing any pneumococcus) were $49.2 \%$ for Aboriginal children and $24.9 \%$ for non-Aboriginal children, with carriage rates increasing with age as previously reported [11]. A total of 547 distinct pneumococcal isolates were identified and subject to further analysis.

\section{Pneumococcal serotypes}

The prevalence (\% of samples) of pneumococcal serotypes (7vPCV serotypes, non-7v PCV13 serotypes, and non-vaccine types) in study participants is shown in Fig. 1, with full data available in Additional file 1: Table S2. Overall, 18.8 \% (95 \% CI 15.6-22.4) of samples from Aboriginal children contained $7 \mathrm{vPCV}$ serotypes compared to $15.7 \%$ (95 \% CI 13.6-18.0) of samples from non-Aboriginal children. There were no significant differences in the prevalence of $7 \mathrm{vPCV}$ between Aboriginal and non-Aboriginal groups when examined in different age groups ( $<6$ months $17 \%$ vs $10 \%, 6-<12$ months $21 \%$ vs $23 \%$, and $\geq 12$ months $22 \%$ in both). There were also no differences in prevalence of the most common serotype, namely $6 \mathrm{~B}$, between Aboriginal and nonAboriginal children in the 3 age groups $(<6$ months 3 $4 \%$, 6-<12 months $11 \%, \geq 12$ months $8-10 \%$ ). Data for other individual serotypes were too sparse to investigate in different age groups. For the additional six serotypes contained in 13vPCV, rates were $9.7 \%$ (95 \% CI 7.4-12.6) from Aboriginal children and $2.7 \%$ (95 \% CI 1.8-3.9) from non-Aboriginal children (note that serotype 5 was not detected in this study). Non-vaccine serotypes were more common in samples from Aboriginal children (21.9 \% [95 \% CI 18.5-25.8]) compared to non-Aboriginal children (7.1\% [95 \% CI 5.7-8.8]), with similar patterns in different age groups. A broader range of serotypes was seen in Aboriginal children (33 different serotypes in 506 samples) than in non-Aboriginal children (29 serotypes in 1,045 samples, $p=0.0004$ ). Serotypes $6 \mathrm{~A}, 19 \mathrm{~A}, 16 \mathrm{~F}, 11 \mathrm{~A}$, $33 \mathrm{~F}, 9 \mathrm{~V}$, and non-typeable pneumococci were more commonly found in samples from Aboriginal than non- 


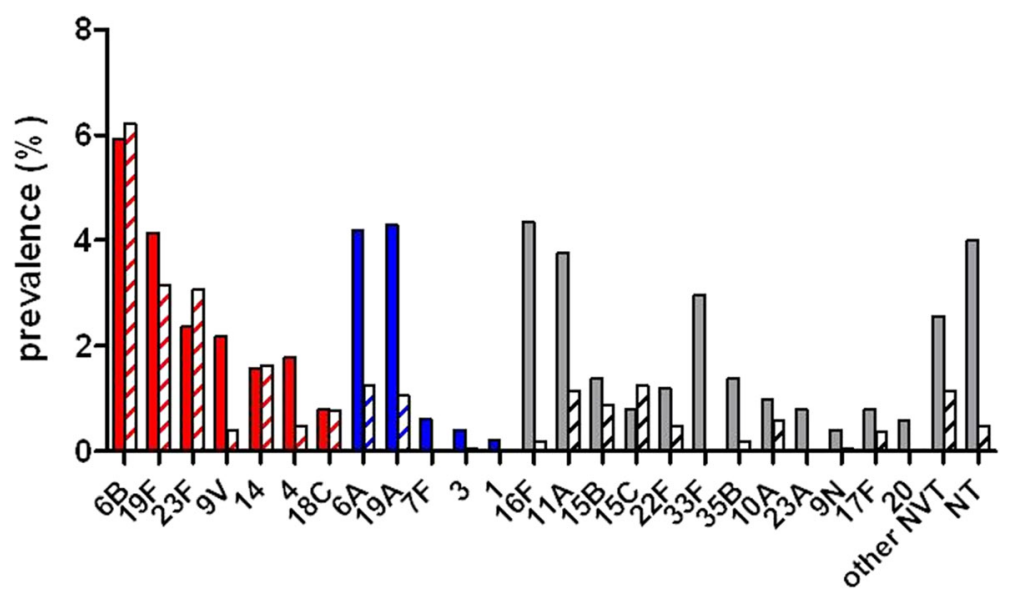

Fig. 1 Prevalence (\% of samples) of pneumococcal serotypes in carriage samples collected from Aboriginal (solid bars) and non-Aboriginal (hashed bars) study participants (1999-2005). 7VPCV serotypes are shown in red, with the additional serotypes contained in 13VPCV shown in blue and non-vaccine types (NVT) shown in grey. NT = non-typeable

Aboriginal children. Twenty-five (4.9\%) samples from Aboriginal children yielded multiple pneumococcal serotypes (24 samples with two different serotypes and one sample with three different serotypes). Twelve (1.1\%) samples from non-Aboriginal children produced two different serotypes.

\section{Antimicrobial susceptibility}

A total of 526 pneumococcal isolates from 507 samples were tested for susceptibility to penicillin, erythromycin, tetracycline, cotrimoxazole, chloramphenicol, and ceftriaxone. Rifampicin and vancomycin susceptibility was tested for on 478 and 479 isolates, respectively. All isolates were susceptible to ceftriaxone, rifampicin, and vancomycin.
Results for other antimicrobials are summarised in Table 1, with detailed results by serotype shown in Additional file 1: Tables S3 and S4. Overall, 127 (24.1\%) isolates showed reduced susceptibility to penicillin, $73(13.9 \%)$ to erythromycin, $78(14.8 \%)$ to tetracycline and $147(27.9 \%)$ to cotrimoxazole. There were differences in antimicrobial susceptibility between pneumococci isolated from Aboriginal and non-Aboriginal children. All isolates from Aboriginal children were susceptible to chloramphenicol, whereas $13.2 \%$ of isolates from non-Aboriginal children displayed reduced susceptibility. Reduced penicillin susceptibility of serotypes $19 \mathrm{~F}$ and $19 \mathrm{~A}$ was more common and that of serotype $6 \mathrm{~B}$ less common in Aboriginal than in nonAboriginal children (19F: $70 \%$ vs. $39 \%$; 19 A $64 \%$ vs. $18 \%$;

Table 1 Reduced antimicrobial susceptibility of Streptococcus pneumoniae in nasopharyngeal samples from Aboriginal and nonAboriginal children

\begin{tabular}{|c|c|c|c|c|c|c|}
\hline \multirow[t]{2}{*}{ Isolate type } & \multirow{2}{*}{$\begin{array}{l}\text { Number of } \\
\text { isolates }\end{array}$} & \multicolumn{5}{|c|}{$\%$ with reduced susceptibility to antimicrobial agent } \\
\hline & & Penicillin $^{a}$ & Erythromycin & Tetracycline & Cotrimoxazole & Chloramphenicol \\
\hline \multicolumn{7}{|l|}{ 7vPCV types } \\
\hline Aboriginal & 92 & 31.5 & 7.6 & 17.4 & 35.9 & 0.0 \\
\hline Non-Aboriginal & 162 & 35.2 & 26.5 & 27.2 & 43.8 & 21.6 \\
\hline \multicolumn{7}{|l|}{ Non-vaccine types } \\
\hline Aboriginal & 151 & 15.2 & 4.0 & 3.3 & 4.6 & 0.0 \\
\hline Non-Aboriginal & 97 & 3.1 & 6.2 & 3.1 & 13.4 & 0.0 \\
\hline \multicolumn{7}{|l|}{ Non-typeable } \\
\hline Aboriginal & 18 & 66.7 & 50.0 & 27.8 & 72.2 & 0.0 \\
\hline Non-Aboriginal & 5 & 60.0 & 40.0 & 60.0 & 80.0 & 0.0 \\
\hline \multicolumn{7}{|l|}{ All pneumococci } \\
\hline Aboriginal & 261 & 24.5 & 8.4 & 10.7 & 22.6 & 0.0 \\
\hline Non-Aboriginal $^{b}$ & 265 & 23.8 & 19.2 & 18.9 & 33.2 & 13.2 \\
\hline
\end{tabular}

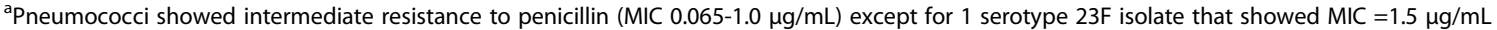
${ }^{\mathrm{b}}$ Includes 1 isolate not serotyped 
6B $21 \%$ vs. $59 \%)$. Cotrimoxazole resistance was present in almost half of the serotype $6 \mathrm{~B}$ isolates from Aboriginal children and $74 \%$ of those from non-Aboriginal children. Of note, $65 \%$ of non-typeable pneumococci isolated from Aboriginal and non-Aboriginal children had reduced susceptibility to penicillin and $74 \%$ had reduced susceptibility to cotrimoxazole. Overall, $5 \%$ of 503 serotypeable pneumococci were resistant to two antimicrobials and a further $9 \%$ to three antimicrobials. Equivalent figures for 23 non-typeable pneumococci were $30 \%$ and $43 \%$, respectively.

There were 33 isolates (serotypes $6 \mathrm{~B}, n=27 ; 23 \mathrm{~F}, n=5$; 19F, $n=1$ ) from 20 non-Aboriginal children, which showed reduced susceptibility to penicillin, tetracycline, erythromycin, cotrimoxazole and chloramphenicol (6.3\% of all isolates, $12.5 \%$ of isolates from non-Aboriginal children). This multi-resistance pattern was not seen in any isolates from Aboriginal children.

\section{Molecular epidemiology}

Using PFGE, 67 different molecular types of S. pneumoniae were identified among the 199 isolates examined (Additional file 1: Table S5). Of these, 30 were represented once and 14 types were seen five or more times. All 7vPCV serotypes in this population were quite variable except 18C. Only one molecular type (72) was found in both a vaccine (6B) and a non-vaccine (10A) serotype; these isolates were not from the same child.

MLST was performed on 12 serotype $6 \mathrm{~B}$ isolates and 18 serotype 19A isolates (6 of which were collected in 2008) (Table 2). The multiresistant $6 \mathrm{~B}$ clone identified as molecular type 58 by PFGE was revealed to be ST90, a globally distributed clone also known as Spain ${ }^{6 \mathrm{~B}}-2$. Interestingly, ST90 was only found in non-Aboriginal children, whereas ST185, a globally distributed clone known as $\mathrm{S}$. Africa ${ }^{6 \mathrm{~B}}-8$ was isolated from both Aboriginal and non-Aboriginal children.

The 6B isolates clustered into two broad clonal complexes, one related to ST385 and one related to ST90. These two clonal complexes were evenly distributed throughout the study period. Most of the 19A isolates were related to ST199, although one 19A isolate was ST162, which is mainly associated with serotypes 9V and 19F [33]. Three isolates with distinct PFGE molecular types were all ST199. The six more recent 19A isolates examined belonged to ST202 and ST320. No serotype $6 \mathrm{~B}$ isolates were identified in 2008 following widespread use of $7 \mathrm{vPCV}$.

\section{Pneumococcal carriage and vaccination}

A higher proportion of Aboriginal than non-Aboriginal children received $7 \mathrm{vPCV}$, they were older than nonAboriginal children at time of receiving each dose of

Table 2 Genotypes and antimicrobial resistance of select 6B and 19A isolates

\begin{tabular}{|c|c|c|c|c|c|}
\hline Isolates (n) & Ethnicity & Serotype & Antimicrobial resistance ${ }^{a}$ & PFGE type ${ }^{b}$ & Sequence Type ${ }^{c}$ \\
\hline 1 & Aboriginal & $6 \mathrm{~B}$ & cotrimoxazole $(I)$, tetracycline $(R)$ & 59 & 385 \\
\hline 1 & Aboriginal & $6 \mathrm{~B}$ & tetracycline $(R)$ & ND & 385 \\
\hline 4 & Aboriginal (3), non-Aboriginal (1) & $6 \mathrm{~B}$ & cotrimoxazole $(R)$ & $60(2), N D(2)$ & 185 (DLV 385) \\
\hline 1 & Aboriginal & $6 \mathrm{~B}$ & cotrimoxazole $(R)$ & ND & 4276 (DLV 385) \\
\hline 4 & Non-Aboriginal & $6 \mathrm{~B}$ & multiresistant & $58, N D$ & 90 \\
\hline 1 & Non-Aboriginal & $6 \mathrm{~B}$ & multiresistant & ND & $10265^{d+}$ (SLV 90) \\
\hline 1 & Aboriginal & $19 \mathrm{~A}$ & none & 30 & 199 \\
\hline 1 & Aboriginal & $19 \mathrm{~A}$ & none & 28 & 199 \\
\hline 1 & Non-Aboriginal & $19 \mathrm{~A}$ & none & 11 & 199 \\
\hline 1 & Aboriginal & $19 \mathrm{~A}$ & cotrimoxazole (R) & 31 & 876 (SLV 199) \\
\hline 1 & Non-Aboriginal & $19 \mathrm{~A}$ & cotrimoxazole (R) & ND & $10264^{d}$ (DLV 199) \\
\hline 2 & Aboriginal, non-Aboriginal & $19 \mathrm{~A}$ & none & 18 & 172 \\
\hline 1 & Aboriginal & $19 A$ & none & 34 & $10262^{d}$ \\
\hline 2 & Aboriginal & $19 \mathrm{~A}$ & none & ND & $10263^{d}$ (SLV 10262) \\
\hline 1 & Non-Aboriginal & $19 \mathrm{~A}$ & cotrimoxazole $(R)$ & ND & 162 \\
\hline 4 (3 from 2008) & Aboriginal & $19 \mathrm{~A}$ & cotrimoxazole $(R)$, tetracycline $(R)$ & ND & 202 \\
\hline 3 (from 2008) & Aboriginal & $19 A$ & multiresistant & ND & 320 \\
\hline
\end{tabular}

a/ Intermediate, $R$ Resistant, multiresistant resistant to cotrimoxazole, erythromycin, and tetracycline, and chloramphenicol and/or penicillin

${ }^{\mathrm{b}} N D$ not determined

${ }^{\mathrm{C}} S L V$ single locus variant, $D L V$ double locus variant

${ }^{d} S T$ first reported in this study 
$7 \mathrm{vPCV}$ and there was no difference in time from receiving $7 \mathrm{vPCV}$ to sample collection between Aboriginal and non-Aboriginal children (Additional file 1: Table S1). Table 3 shows pneumococcal carriage in unimmunised children and according to number of doses among those who received their first dose of $7 \mathrm{vPCV}$ before age 12 months. Serotypes were grouped as $7 \mathrm{vPCV}$ and non$7 \mathrm{vPCV}$ types for this analysis as numbers were too small to analyse individually for most serotypes. Similarly, children receiving 1 and 2 doses of $7 \mathrm{vPCV}$ were grouped due to small numbers. There were 415 samples from Aboriginal children and 1,010 samples from non-Aboriginal children included in this analysis ( $82 \%$ and $97 \%$ of all study samples, respectively). From this cohort of Aboriginal children, pneumococci were isolated from 105 (40.9 \%) samples from unvaccinated children, 44 (57.1\%) samples from those who had received one or two doses of $7 \mathrm{vPCV}$, and $53(65.4 \%)$ samples from those who had received 3 doses. Equivalent numbers for the non-Aboriginal children were 183 (22.3\%), 33 (37.1\%), and 33 (32.4\%), respectively. Note that the increased pneumococcal carriage with more doses is related to the increase in carriage prevalence with age during the first year of life [11].

A higher proportion of samples from Aboriginal children had non-7vPCV serotypes after receiving 3 doses of vaccine $(46.9 \%$, $95 \%$ CI 36.4-57.7 \%) compared with samples from those who were not vaccinated $(24.5 \%$, $95 \%$ CI 19.6-30.1\%), while carriage of 7vPCV serotypes was lower following 3 doses of vaccine than in unvaccinated children (9.9 \% [95 \% CI 4.9-18.5\%] vs. $17.9 \%$ [95 \% CI 13.7-23.1\%]). In contrast, similar proportions of $7 \mathrm{vPCV}$ and non-7vPCV pneumococcal serotypes were found in unvaccinated and fully vaccinated non-Aboriginal children. After controlling for age and accounting for repeated sampling, the odds of isolating $7 \mathrm{vPCV}$ pneumococcal serotypes in samples from Aboriginal children were about five times less after three doses of vaccine than in samples from unvaccinated children, and the odds of isolating non-7vPCV types were 2.5 times greater (Table 4). Similar results were not seen with samples taken from non-Aboriginal children. However, non-Aboriginal children who received 1-2 doses of $7 \mathrm{vPCV}$ had an increased odds of carrying $7 \mathrm{vPCV}$ serotypes.

\section{Discussion}

To our knowledge, this is the only study to date comparing the characteristics of pneumococci isolated from the upper respiratory tract in indigenous children with those in nonindigenous children living in the same geographic area, and notably in an arid zone of Australia, for which there is a dearth of any carriage data. In addition to higher carriage rates, the distribution of pneumococcal serotypes was more diverse, and carriage of non-typeable strains and simultaneous carriage of multiple serotypes were more common in Aboriginal than in non-Aboriginal children.

The serotype distribution and antimicrobial susceptibility patterns differed between Aboriginal and non-Aboriginal children. Of note, non-PCV7 serotypes 16F, 19A, 6A, and 33F (known to be replacement serotypes following widespread use of PCVs [34, 35]) were more common in Aboriginal than in non-Aboriginal children. These differences may relate, in part at least, to vaccination status: more Aboriginal children received three doses of $7 \mathrm{vPCV}$, and these fully vaccinated children were less likely to carry $7 \mathrm{vPCV}$ serotypes (Table 4), providing evidence of vaccine impact on carriage. However, unvaccinated Aboriginal children had higher carriage rates overall and higher carriage of non-7vPCV serotypes (more serotype diversity) than unvaccinated non-Aboriginal children, indicating some baseline differences in pneumococcal carriage.

Non-Aboriginal children receiving 1 or 2 doses of $7 \mathrm{vPCV}$ had increased odds of carrying $7 \mathrm{vPCV}$ serotypes when compared to those who had had no 7vPCV. This finding was unexpected and the reasons are unclear. It may relate

Table 3 Proportion of samples with 7vPCV or non-7vPCV serotypes in Aboriginal and non-Aboriginal children who received 0, 1-2, or 3 doses of 7VPCV

\begin{tabular}{|c|c|c|c|c|c|}
\hline & & \multicolumn{3}{|l|}{ Doses } & \multirow[t]{2}{*}{ Total } \\
\hline & & 0 & $1-2$ & 3 & \\
\hline \multirow[t]{3}{*}{ Aboriginal } & Samples (n) & $257(\%)^{a}$ & $77(\%)$ & $81(\%)$ & $415(\%)$ \\
\hline & 7vPCV serotypes & $46(17.9)$ & $16(20.8)$ & $8(9.9)$ & $70(16.9)$ \\
\hline & Non-7vPCV serotypes & $63(24.5)$ & $27(35.1)$ & $38(46.9)$ & $128(30.8)$ \\
\hline \multirow[t]{3}{*}{ Non-Aboriginal } & Samples (n) & $819(\%)$ & 89 (\%) & $102(\%)$ & $1010(\%)$ \\
\hline & 7vPCV serotypes & $110(13.4)$ & $24(27.0)$ & $18(17.6)$ & $152(15.0)$ \\
\hline & Non-7vPCV serotypes & $72(8.8)$ & $11(12.4)$ & $14(13.7)$ & $97(9.6)$ \\
\hline
\end{tabular}

\footnotetext{
$\mathrm{a}_{\%}=$ proportion of samples
}

Note: To avoid potential bias related to health service utilization, data presented here are from children who either never received 7vPCV or received their first dose of 7vPCV before age 12 months. Among 7vPCV recipients, only samples collected $>14$ days after $7 \mathrm{vPCV}$ administration were considered post-vaccine Some nasopharyngeal aspirates included more than one 7vPCV or non-7vPCV serotypes or both 7vPCV and non-7vPCV serotypes. Non-typeable pneumococci were excluded 
Table 4 Odds Ratios for carriage of S. pneumoniae serotypes in nasopharyngeal samples by vaccine doses received

\begin{tabular}{llllll}
\hline Serotype & \multicolumn{2}{l}{ Dose $1 / 2 \mathrm{OR}^{\mathrm{a}}(95 \% \mathrm{Cl})$} & & \multicolumn{2}{l}{ Dose $3 \mathrm{OR}(95 \% \mathrm{Cl})$} \\
\cline { 2 - 3 } & Aboriginal & Non-Aboriginal & & Aboriginal & Non-Aboriginal \\
\hline 7vPCV serotypes & $0.90(0.43,1.88)$ & $1.93(1.13,3.32)$ & $0.19(0.08,0.44)$ & $0.83(0.41,1.66)$ \\
Non-7vPCV serotypes & $1.83(1.04,3.20)$ & $1.25(0.57,2.74)$ & $2.50(1.17,5.35)$ & $1.19(0.65,2.17)$ \\
\hline
\end{tabular}

${ }^{\mathrm{a}} \mathrm{OR}$ odds ratio from logistic regression, adjusting for age and age-squared and accounting for repeated sampling of individuals, with unvaccinated as the reference category. Non-typeable pneumococci were excluded

to temporal variation in carriage of certain serotypes or association between health-seeking behaviour and carriage (i.e. a small proportion of non-Aboriginal parents chose to have their children vaccinated and those who were vaccinated may have been more sickly and more likely to carry pneumococci), or the lack of herd effects in this community as $7 \mathrm{vPCV}$ was not included in the national immunization schedule for non-Aboriginal children during the study period. But the small number of non-Aboriginal children in this study who received 7vPCV precludes further analysis.

Generally, reduced susceptibility to antimicrobial agents was observed more often in $S$. pneumoniae carried by non-Aboriginal than Aboriginal children, with all multiresistant strains isolated from non-Aboriginal children. An exception was serotype $19 \mathrm{~F}$ which was more commonly resistant when carried by Aboriginal children. The antimicrobial prescription frequency was similar in Aboriginal and non-Aboriginal children in the study, but there are no available data on specific antimicrobial agents [36]. The reasons for the differences in susceptibility to antimicrobial agents are unclear, but may relate to differences in circulating pneumococcal clonal types between the two population groups or potential differences in the classes of antibiotics prescribed.

Carriage of serotype 6B was common in both Aboriginal and non-Aboriginal children, but the multi-resistant clone ST90 was only observed in non-Aboriginal children. A multiple-drug resistant clone of $6 \mathrm{~B}$ was known to be circulating in Australia from 1988 to 1997 [37]; however, no MLST results are available from this time period so it is not known whether this clone was related to ST90. Reduced susceptibility to antimicrobials was commonly observed in non-typeable isolates from both populations, consistent with reports identifying non-typeable pneumococci as a major reservoir for antimicrobial resistance genes [38, 39].

As expected, the widespread use of PCV in more recent years has altered serotype prevalence in carriage. Surveillance of pneumococcal carriage in Aboriginal people in Western Australia from 2008 to 2011 found a 7 \% prevalence in $7 \mathrm{vPCV}$ serotypes across varying age groups, with serotypes $19 \mathrm{~A}, 16 \mathrm{~F}$ and $6 \mathrm{C}$ the most common in children under five years old [32]. Further shifts in serotype distribution and a reduction in carriage of 19A have been reported following the switch to PCV13 in 2011 [40]. MLST analysis of serotype 19A isolates suggests that circulating strains may have changed following 7vPCV introduction. Only a small number of isolates was examined, so expanded molecular epidemiological studies would be needed to investigate whether selective pressure following PCV introduction results in clonal expansion, as has been observed in other settings [41].

Limitations of this study include the fact that antiserum to serotype $6 \mathrm{C}$ (required to differentiate between $6 \mathrm{~A}$ and $6 \mathrm{C}$ ) was not available at the time of sample analysis, so this serotype would not have been detected. It is also likely that simultaneous carriage of multiple serotypes was underestimated [42]. Non-typeable pneumococci were not subject to genetic analysis, therefore could represent both isolates not producing capsule and "true" nontypeable pneumococci that lack capsule synthesis genes. More sophisticated serotyping methodologies are now available [43]. Antibiotic susceptibility data were not examined according to vaccine status, due to small numbers within each dosing group.

An overall reduction in invasive pneumococcal disease (IPD) and a reduction in IPD caused by $7 \mathrm{vPCV}$ serotypes have been observed in the post-PCV years in Australia, although IPD due to non-vaccine serotypes has increased [13, 44]. The switch to PCV13 in 2011 has led to further reductions in IPD, particularly in children under five years of age [45]. Although a gap still remains, the disparity in pneumonia hospitalisations between Australian Aboriginal and non-Aboriginal children has declined over time, likely due in part to PCV introduction [46].

\section{Conclusions}

This study identified important differences in pneumococcal serotypes, genotypes, and antimicrobial susceptibility between Aboriginal and non-Aboriginal children living in the same region before widespread $7 \mathrm{vPCV}$ use. Ongoing surveillance of pneumococcal carriage is warranted to monitor potential increases in antimicrobial resistance and changes in serotype distribution that could impact on pneumococcal disease and health outcomes, and to help in the continual development of effective vaccines. Data reported here provide a useful baseline comparator, as well as insight into some of the differences in S. pneumoniae carried by Aboriginal and non-Aboriginal children in Australia. 


\section{Additional file}

Additional file 1: Table S1. 7vPCV vaccination characteristics of the study participants. Table S2. Prevalences of pneumococcal serotypes found in the respiratory tract of study participants 1999-2005. Table S3. Reduced antimicrobial susceptibility of Streptococcus pneumoniae in nasopharyngeal samples from Aboriginal children reported by serotype. Table S4. Reduced antimicrobial susceptibility of Streptococcus pneumoniae in nasopharyngeal samples from non-Aboriginal children reported by serotype. Table S5. The molecular type by pulse-field gel electrophoresis (PFGE) of 199 S. pneumoniae isolates reported by serotype. (DOCX $26 \mathrm{~kb}$ )

\section{Abbreviations}

23vPPV: 23-valent pneumococcal polysaccharide vaccine; 7vPCV: 7-valent pneumococcal conjugate vaccine; Cl: confidence interval; IPD: invasive pneumococcal disease; MIC: minimum inhibitory concentration; MLST: multilocus sequence typing; NPA: nasopharyngeal aspirate; OM: otitis media; OR: odds ratio; PCV: pneumococcal conjugate vaccine; PFGE: pulse field gel electrophoresis

\section{Acknowledgements}

This study resulted from the collaborative work of the Kalgoorlie Otitis Media Research Project Team (listed in reference \# [11]); however, we particularly thank crucial field staff: Dimity Elsbury, the late Janine Finucane, Annette Stokes and Ruth Monck. We thank Lyn O'Reilly for assistance with bacterial typing.

\section{Funding}

This study was funded through the Australian National Health and Medica Research Council project grant \#212044 and two Healthway grants (\#6028 and \#10564). DL was funded through National Health and Medical Research Council program grant \#353514. Wyeth Australia provided Prevenar ${ }^{\mathrm{TM}}$ for non-Aboriginal study participants. MLST work was supported by the Victorian Government's Operational Infrastructure Support Program. AJL was supported by a National Health and Medical Research Council Career Development Award (\#283312). KC was supported through the Masters of Applied Epidemiology program funded by the Australian Government. The funders had no role in study design, collection and analysis of data, decision to publish, or writing of the manuscript.

\section{Availability of data and materials}

The dataset supporting the conclusions of this article is available in the Dryad Digital Repository, http://dx.doi.org/10.5061/dryad.4nn26.

\section{Authors' contributions}

Conception, generation and design of the research plan: DL, TVR, AJL, AWC PJ Data collection: KC, JB, DM, EMD Data analysis: PJ, EMD, DL Drafting of manuscript: EMD, DL. All authors performed critical review of the manuscript.

\section{Competing interests}

DL has previously been a member of the GSK Australia PneumococcalHaemophilus influenzae-Protein D conjugate vaccine ("Phid-CV") Advisory Panel, has received support from Pfizer Australia and GSK Australia to attend conferences, has received an honorarium from Merck Vaccines to give a seminar at their offices in Pennsylvania and to attend a conference, and is an investigator on an investigator-initiated research grant funded by Pfizer Australia. AJL has received research funding and support to attend conferences from GlaxoSmithKline and Pfizer Australia. AWC has previously been a member of the GSK Advisory Panel for the 10 valent pneumococcal conjugate vaccine and presented at Symposia. He received an honorarium from GSK to undertake these activities. He has also chaired a Symposium on pneumonia for Pfizer Australia. No honorarium was accepted. All other authors have no competing interests

\section{Consent for publication}

Not applicable

\section{Ethics approval and consent to participate}

Ethical approval to conduct this study was given by the Western Australian Aboriginal Health and Information Ethics Committee, the Northern Goldfields Health Service and Nursing Education Ethics Committee in Kalgoorlie, Princess
Margaret Hospital Ethics Committee and the Confidentiality of Health Information Committee of the Health Department of WA. Written informed consent was provided by participants' guardians.

\section{Author details}

${ }^{1}$ Pneumococcal Research, Murdoch Childrens Research Institute, Parkville, VIC, Australia. ${ }^{2}$ Victorian Infectious Disease Reference Laboratory at the Peter Doherty Institute for Infection and Immunity, Melbourne, VIC, Australia. ${ }^{3}$ Microbiology \& Immunology, School of Pathology \& Laboratory Medicine, The University of Western Australia, Crawley, WA, Australia. ${ }^{4}$ Department of Microbiology, PathWest Laboratory Medicine, Queen Elizabeth II Medical Centre, Nedlands, WA, Australia. ${ }^{5}$ Child Health Division, Menzies School of Health Research, Darwin, NT, Australia. ${ }^{6}$ School of Medicine and Menzies Health Institute Queensland, Griffith University, Southport, QLD, Australia. ${ }^{7}$ Public Health Bacteriology Laboratory, Centre for Public Health Sciences, Coopers Plains, QLD, Australia. ${ }^{8}$ Telethon Kids Institute, The University of Western Australia, Subiaco, WA, Australia.

Received: 18 December 2015 Accepted: 18 August 2016

Published online: 05 September 2016

\section{References}

1. Liu L, Oza S, Hogan D, Perin J, Rudan I, Lawn JE, et al. Global, regional, and national causes of child mortality in 2000-13, with projections to inform post-2015 priorities: an updated systematic analysis. Lancet. 2015;385:43040. PMID:25280870.

2. O'Grady KA, Taylor-Thomson DM, Chang AB, Torzillo PJ, Morris PS, Mackenzie GA, et al. Rates of radiologically confirmed pneumonia as defined by the World Health Organization in Northern Territory Indigenous children. Med J Aust. 2010;192:592-5. PMID:20477736.

3. Alaghehbandan R, Gates KD, MacDonald D. Hospitalization due to pneumonia among Innu, Inuit and non-Aboriginal communities, Newfoundland and Labrador, Canada. Int J Infect Dis. 2007;11:23-8. PMID: 16533615, http://dx.doi.org/10.1016/j.ijid.2005.09.003.

4. File TM. Community-acquired pneumonia, Lancet. 2003:362:1991-2001. PMID:14683661.

5. Michelow IC, Olsen K, Lozano J, Rollins NK, Duffy LB, Ziegler T, et al. Epidemiology and clinical characteristics of community-acquired pneumonia in hospitalized children. Pediatrics. 2004;113:701-7. PMID:15060215.

6. Ghaffar F, Barton T, Lozano J, Muniz LS, Hicks P, Gan V, et al. Effect of the 7valent pneumococcal conjugate vaccine on nasopharyngeal colonization by Streptococcus pneumoniae in the first 2 years of life. Clin Infect Dis. 2004;39: 930-8. PMID:15472842, http://dx.doi.org/10.1086/423379.

7. Millar EV, O'Brien KL, Watt JP, Bronsdon MA, Dallas J, Whitney CG, et al. Effect of community-wide conjugate pneumococcal vaccine use in infancy on nasopharyngeal carriage through 3 years of age: a cross-sectional study in a high-risk population. Clin Infect Dis. 2006;43:8-15. PMID:16758412, http://dx.doi.org/10.1086/504802.

8. Leach AJ, Boswell JB, Asche V, Nienhuys TG, Mathews JD. Bacterial colonization of the nasopharynx predicts very early onset and persistence of otitis media in Australian Aboriginal infants. Pediatr Infect Dis J. 1994;13: 983-9. PMID:7845752, http://dx.doi.org/10.1097/00006454-199411000-00009.

9. Simell B, Auranen K, Käyhty H, Goldblatt D, Dagan R, O'Brien KL, Group PC. The fundamental link between pneumococcal carriage and disease. Expert Rev Vaccines. 2012;11:841-55. PMID:22913260, http://dx.doi.org/10.1586/erv.12.53.

10. Ruohola A, Pettigrew MM, Lindholm L, Jalava J, Räisänen KS, Vainionpää $R$, et al. Bacterial and viral interactions within the nasopharynx contribute to the risk of acute otitis media. J Infect. 2013;66:247-54. PMID:23266462, http://dx.doi.org/10.1016/j.jinf.2012.12.002.

11. Watson K, Carville K, Bowman J, Jacoby P, Riley TV, Leach AJ, Kalgoorlie Otitis Media Research Project Team, et al. Upper respiratory tract bacterial carriage in Aboriginal and non-Aboriginal children in a semi-arid area of Western Australia. Pediatr Infect Dis J. 2006;25:782-90. PMID:16940834, http://dx.doi.org/10.1097/01.inf.0000232705.49634.68.

12. Barry C, Krause VL, Cook HM, Menzies Rl. Invasive pneumococcal disease in Australia 2007 and 2008. Commun Dis Intell Q Rep. 2012:36:E151-65. PMID:23186214.

13. Lehmann D, Willis J, Moore HC, Giele C, Murphy D, Keil AD, et al. The changing epidemiology of invasive pneumococcal disease in Aboriginal and nonAboriginal Western Australians from 1997 through 2007 and emergence of nonvaccine serotypes. Clin Infect Dis. 2010:50:1477-86. PMID:20420501, http://dx.doi.org/10.1086/652440. 
14. Black S, Shinefield H, Fireman B, Lewis E, Ray P, Hansen JR, Northern California Kaiser Permanente Vaccine Study Center Group, et al. Efficacy, safety and immunogenicity of heptavalent pneumococcal conjugate vaccine in children. Pediatr Infect Dis J. 2000;19:187-95. PMID:10749457, http://dx.doi.org/10.1097/00006454-200003000-00003.

15. Hennessy TW, Singleton RJ, Bulkow LR, Bruden DL, Hurlburt DA, Parks D, et al. Impact of heptavalent pneumococcal conjugate vaccine on invasive disease, antimicrobial resistance and colonization in Alaska Natives: progress towards elimination of a health disparity. Vaccine. 2005;23:5464-73. PMID:16188350, http://dx.doi.org/10.1016/j.vaccine.2005.08.100.

16. Eskola J, Kilpi T, Palmu A, Jokinen J, Haapakoski J, Herva E, Finnish Otitis Media Study Group, et al. Efficacy of a pneumococcal conjugate vaccine against acute otitis media. N Engl J Med. 2001;344:403-9. PMID:11172176, http://dx.doi.org/10.1056/NEJM200102083440602.

17. Ben-Shimol S, Givon-Lavi N, Leibovitz E, Raiz S, Greenberg D, Dagan R. Nearelimination of otitis media caused by 13-valent pneumococcal conjugate vaccine $(\mathrm{PCV}$ ) serotypes in southern Israel shortly after sequential introduction of 7-valent/13-valent PCV. Clin Infect Dis. 2014;59:1724-32. PMID:25159581, http://dx.doi.org/10.1093/cid/ciu683.

18. Black SB, Shinefield HR, Ling S, Hansen J, Fireman B, Spring D, et al. Effectiveness of heptavalent pneumococcal conjugate vaccine in children younger than five years of age for prevention of pneumonia. Pediatr Infect Dis J. 2002;21:810-5. PMID:12352800, http://dx.doi.org/10. 1097/00006454-200209000-00005.

19. Lucero MG, Nohynek H, Williams $G$, Tallo V, Simões EA, Lupisan $S$, et al. Efficacy of an 11-valent pneumococcal conjugate vaccine against radiologically confirmed pneumonia among children less than 2 years of age in the Philippines: a randomized, double-blind, placebocontrolled trial. Pediatr Infect Dis J. 2009;28:455-62. PMID:19483514, http://dx.doi.org/10.1097/INF.0b013e31819637af.

20. Pelton SI, Loughlin AM, Marchant CD. Seven valent pneumococcal conjugate vaccine immunization in two Boston communities: changes in serotypes and antimicrobial susceptibility among Streptococcus pneumoniae isolates. Pediatr Infect Dis J. 2004;23:1015-22. PMID:15545856, http://dx.doi.org/10.1097/01.inf. $0000143645.58215 . f 0$

21. Leach AJ, Morris PS, McCallum GB, Wilson CA, Stubbs L, Beissbarth J, et al. Emerging pneumococcal carriage serotypes in a high-risk population receiving universal 7-valent pneumococcal conjugate vaccine and 23-valent polysaccharide vaccine since 2001. BMC Infect Dis. 2009;9:121. PMID: 19650933, http://dx.doi.org/10.1186/1471-2334-9-121.

22. van Hoek AJ, Sheppard CL, Andrews NJ, Waight PA, Slack MPE, Harrison TG, et al. Pneumococcal carriage in children and adults two years after introduction of the thirteen valent pneumococcal conjugate vaccine in England. Vaccine. 2014;32(34):4349-55.

23. Australian Technical Advisory Group on Immunisation. The Australian Immunisation Handbook. 10th ed. Canberra: Australian Government Department of Health; 2013.

24. Lehmann D, Arumugaswamy A, Elsbury D, Finucane J, Stokes A, Monck R, et al. The Kalgoorlie Otitis Media Research Project: rationale, methods, population characteristics and ethical considerations. Paediatr Perinat Epidemiol. 2008;22 60-71. PMID:18173785, http://dx.doi.org/10.1111/j.1365-3016.2007.00891.x.

25. Jacoby P, Carville KS, Hall G, Riley TV, Bowman J, Leach AJ, Kalgoorlie Otitis Media Research Project Team, et al. Crowding and other strong predictors of upper respiratory tract carriage of otitis media-related bacteria in Australian Aboriginal and non-Aboriginal children. Pediatr Infect Dis J. 2011;30:480-5. PMID:21593705.

26. Carville KS, Bowman JM, Lehmann D, Riley TV. Comparison between nasal swabs and nasopharyngeal aspirates for, and effect of time in transit on, isolation of Streptococcus pneumoniae, Staphylococcus aureus, Haemophilus influenzae, and Moraxella catarrhalis. J Clin Microbiol. 2007;45:244-5. PMID: 17079497, http://dx.doi.org/10.1128/JCM.01131-06.

27. National Committee for Clinical Laboratory Standards. Performance standards for antimicrobial disk susceptibility tests; approved standard, 7th edition Pennsylvania, USA NCCLS; 2000

28. National Committee for Clinical Laboratory Standards. Performance standards for antimicrobial susceptibility testing; twelfth informational supplement. Pennsylvania, USA: NCCLS; 2002.

29. Sá-Leão R, Tomasz A, Sanches IS, Nunes S, Alves CR, Avô AB, et al. Genetic diversity and clonal patterns among antibiotic-susceptible and -resistant Streptococcus pneumoniae colonizing children: day care centers as autonomous epidemiological units. J Clin Microbiol. 2000;38:4137-44. PMID:11060081.
30. Dunne EM, Ong EK, Moser RJ, Siba PM, Phuanukoonnon S, Greenhill AR, et al. Multilocus sequence typing of Streptococcus pneumoniae by use of mass spectrometry. J Clin Microbiol. 2011;49:3756-60. PMID:21880964, http://dx.doi.org/10.1128/JCM.05113-11.

31. Hanage WP. Serotype replacement in invasive pneumococcal disease: where do we go from here? J Infect Dis. 2007;196:1282-4. PMID:17922390, http://dx.doi.org/10.1086/521630.

32. Collins DA, Hoskins A, Bowman J, Jones J, Stemberger NA, Richmond PC, et al. High nasopharyngeal carriage of non-vaccine serotypes in Western Australian aboriginal people following 10 years of pneumococcal conjugate vaccination. PLoS ONE. 2013;8:e82280. PMID:24349245, http://dx.doi.org/10. 1371/journal.pone.0082280.

33. Brueggemann AB, Griffiths DT, Meats E, Peto T, Crook DW, Spratt BG. Clonal relationships between invasive and carriage Streptococcus pneumoniae and serotype- and clone-specific differences in invasive disease potential. J Infect Dis. 2003;187(9):1424-32.

34. Hicks LA, Harrison LH, Flannery B, Hadler JL, Schaffner W, Craig AS, et al. Incidence of pneumococcal disease due to non-pneumococcal conjugate vaccine (PCV7) serotypes in the United States during the era of widespread PCV7 vaccination, 1998-2004. J Infect Dis. 2007;196:1346-54. PMID: 17922399, http://dx.doi.org/10.1086/521626.

35. Grivea IN, Priftis KN, Giotas A, Kotzia D, Tsantouli AG, Douros K, et al. Dynamics of pneumococcal carriage among day-care center attendees during the transition from the 7-valent to the higher-valent pneumococcal conjugate vaccines in Greece. Vaccine. 2014;32:6513-20. PMID:25252194, http://dx.doi.org/10.1016/j.vaccine.2014.09.016

36. Murigu N. Utilisation of health services by Aboriginal and non-Aboriginal children in the Kalgoorlie Boulder region of Western Australia: Curtin University. 2008.

37. Carlisle JB, Gratten M, Leach AJ. Molecular epidemiology of multiple drug resistant type 6B Streptococcus pneumoniae in the Northern Territory and Queensland, Australia. Epidemiol Infect. 2001;126:25-9. PMID:11293678, http://dx.doi.org/10.1017/S0950268801005106

38. Chewapreecha C, Harris SR, Croucher NJ, Turner C, Marttinen P, Cheng L, et al. Dense genomic sampling identifies highways of pneumococcal recombination. Nat Genet. 2014;46:305-9. PMID:24509479, http://dx.doi.org/10.1038/ng.2895.

39. Marsh R, Smith-Vaughan H, Hare KM, Binks M, Kong F, Warning J, et al. The nonserotypeable pneumococcus: phenotypic dynamics in the era of anticapsular vaccines. J Clin Microbiol. 2010;48:831-5. PMID:20042626, http://dx.doi.org/10.1128/JCM.01701-09.

40. Hoskins A, Collins D, Senasinghe K, Bowman J, Stemberger NA, Jones J, et al. Pneumococcal carriage rates remain high in Western Australian Aboriginal people: 12 years and two vaccines later. Pneumonia. 2014;3:290 [Abstract ISPPD - 0352].

41. Mahjoub-Messai F, Doit C, Koeck J-L, Billard T, Evrard B, Bidet P, et al. Population snapshot of Streptococcus pneumoniae serotype 19A isolates before and after introduction of Seven-Valent Pneumococcal Vaccination for French children. J Clin Microbiol. 2009;47(3):837-40.

42. Huebner RE, Dagan R, Porath N, Wasas AD, Klugman KP. Lack of utility of serotyping multiple colonies for detection of simultaneous nasopharyngeal carriage of different pneumococcal serotypes. Pediatr Infect Dis J. 2000; 19:1017-20. PMID:1 1055610, http://dx.doi.org/10.1097/00006454200010000-00019.

43. Satzke C, Dunne EM, Porter BD, Klugman KP, Mulholland EK. PneuCarriage project group The PneuCarriage Project: a multi-centre comparative study to identify the best serotyping methods for examining pneumococcal carriage in vaccine evaluation studies. PLoS Med. 2015;12, e1001903. PMID: 26575033, http://dx.doi.org/10.1371/journal.pmed.1001903.

44. Williams SR, Mernagh PJ, Lee MH, Tan JT. Changing epidemiology of invasive pneumococcal disease in Australian children after introduction of a 7-valent pneumococcal conjugate vaccine. Med J Aust. 2011;194:116-20. PMID:21299484.

45. de Kluyver R, Enhanced Invasive Pneumococcal Disease Surveillance Working Group. Invasive pneumococcal disease surveillance Australia, 1 January to 31 March 2015. Commun Dis Intell Q Rep. 2015;39(2):E308-11.

46. Moore HC, Lehmann D, de Klerk N, Jacoby P, Richmond PC. Reduction in disparity for pneumonia hospitalisations between Australian indigenous and non-Indigenous children. J Epidemiol Community Health. 2012;66:489-94. PMID:21258115, http://dx.doi.org/10.1136/jech.2010.122762. 